\title{
Contrast-enhanced ultrasound approach to the diagnosis of focal liver lesions: the importance of washout
}

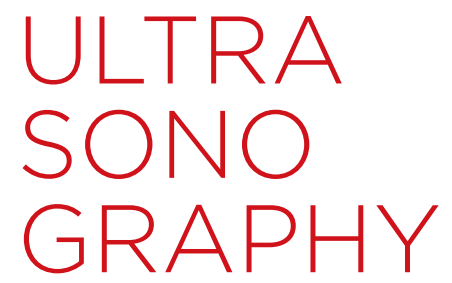

\author{
Hyun Kyung Yang ${ }^{1}$, Peter N. Burns ${ }^{2}$, Hyun-Jung Jang ${ }^{1}$, Yuko Kono ${ }^{3}$, Korosh Khalili', \\ Stephanie R. Wilson ${ }^{4}$, Tae Kyoung Kim ${ }^{1}$ \\ ${ }^{1}$ Joint Department of Medical Imaging, University of Toronto, Toronto; ${ }^{2}$ Department of \\ Medical Biophysics, Sunnybrook Research Institute, University of Toronto, Toronto, Canada; \\ ${ }^{3}$ Departments of Medicine and Radiology, University of California, San Diego, CA, USA; \\ ${ }^{4}$ Diagnostic Imaging, Department of Radiology, University of Calgary, Calgary, Canada
}

Contrast-enhanced ultrasound (CEUS) is a powerful technique for differentiating focal liver lesions (FLLS) without the risks of potential nephrotoxicity or ionizing radiation. In the diagnostic algorithm for FLLs on CEUS, washout is an important feature, as its presence is highly suggestive of malignancy and its characteristics are useful in distinguishing hepatocellular from nonhepatocellular malignancies. Interpreting washout on CEUS requires an understanding that microbubble contrast agents are strictly intravascular, unlike computed tomography or magnetic resonance imaging contrast agents. This review explains the definition and types of washout on CEUS in accordance with the 2017 version of the CEUS Liver Imaging Reporting and Data System and presents their applications to differential diagnosis with illustrative examples. Additionally, we propose potential mechanisms of rapid washout and describe the washout phenomenon in benign entities.

Keywords: Carcinoma, hepatocellular; Neoplasm metastasis; Liver; Ultrasonography; Contrast media; Diagnosis, differential

\section{Introduction}

A growing body of evidence suggests that contrast-enhanced ultrasound (CEUS) is a valuable, accurate, and cost-effective tool for characterizing focal hepatic lesions [1], often complementing indeterminate computed tomography (CT) and magnetic resonance imaging (MRI) results. CEUS can be a useful primary imaging tool for evaluating incidentally detected liver masses or liver masses in young patients and those with renal failure, allergies to contrast agents, or claustrophobia. Typical indications for CEUS for the characterization of focal liver lesions in non-cirrhotic and cirrhotic livers are summarized in the practice guidelines developed by joint World Federation for Ultrasound in Medicine and Biology (WFUMB) and European Federation of Societies for Ultrasound in Medicine and Biopsy (EFSUMB) initiatives [2].

Washout is an important imaging feature for characterizing liver masses and is often the initial
Received: January 15, 2019

Revised: March 13, 2019

Accepted: March 17, 2019

Correspondence to:

Tae Kyoung Kim, MD, PhD, FRCPC,

Department of Medical Imaging,

Toronto General Hospital, 585

University Avenue, Toronto, ON M5G

2N2, Canada

Tel. +1-416-340-3372

Fax. +1-416-593-0502

E-mail: taekyoung.kim@uhn.ca

This is an Open Access article distributed under the terms of the Creative Commons Attribution NonCommercial License (http://creativecommons.org/ licenses/by-nc/4.0/) which permits unrestricted noncommercial use, distribution, and reproduction in any medium, provided the original work is properly cited.

Copyright @ 2019 Korean Society of Ultrasound in Medicine (KSUM)

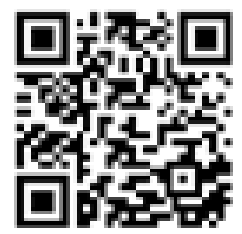

How to cite this article:

Yang HK, Burns PN, Jang HJ, Kono Y, Khalili K, Wilson SR, et al. Contrast-enhanced ultrasound approach to the diagnosis of focal liver lesions: the importance of washout. Ultrasonography. 2019 0ct;38(4):289-301. 
step for differentiating liver masses when using a systematic diagnostic algorithm $[3,4]$. The presence of washout favors malignancy, whereas its absence suggests benignancy [4-6]. Metastases show more rapid washout [7] than hepatocellular carcinoma (HCC), in which the washout is often slow [8]. Washout in malignancy is more consistently demonstrated on CEUS than on CT/MRI due to the strictly intravascular property of the contrast agents [9]. Some malignancies with high vascular permeability and a large extracellular interstitial space, including intrahepatic cholangiocarcinoma (ICC), may fail to show washout on CT or MRI [10-14] due to leakage of the contrast agent through the vascular endothelium and accumulation in the tissue interstitium [9,15-18].

In this article, we briefly cover the typical timing of each vascular phase of CEUS and the properties of contrast agents, and explain the definition and types of washout on CEUS in accordance with the most recent (2017) version of the CEUS Liver Imaging Reporting and Data System (LI-RADS). We also explain the applications of these findings to the differential diagnosis of focal liver lesions with illustrative examples. In addition, we propose potential mechanisms of rapid washout in non-hepatocellular malignancies and describe the washout phenomenon in benign entities.

\section{Contrast Agents and Scan Phases in CEUS}

CEUS uses microbubble contrast agents that are gas-filled microspheres. The microbubbles are strictly intravascular because their size of several micrometers does not permit them to pass through the vascular endothelium into the interstitial space. Currently available second-generation CEUS contrast agents for liver imaging include SonoVue/Lumason (sulfur hexafluoride microbubbles, Bracco, Milano, Italy), and Definity/Luminity (perflutren lipid microspheres, Lantheus Medical Imaging, Billerica, MA, USA). Sonazoid (perfluorobutane, Daiichi-Sankyo, GE, Tokyo, Japan), which is actively used in Japan, South Korea, and Norway, enables additional liver evaluation in the Kupffer phase, as Sonazoid microbubbles are internalized by Kupffer cells. Sonazoid is not included in the 2017 version of the CEUS LI-RADS, although it is expected to be included in the next version of the CEUS LI-RADS.

The enhancement features at CEUS are documented along with the time units after injection of the contrast agent, expressed in seconds or minutes. Time zero is defined as the initiation of the saline flush [19]. The arterial phase starts at 10-20 seconds and lasts up to $30-45$ seconds $[2,19]$. The portal venous phase starts at $30-45$ seconds and lasts until 2 minutes $[2,19]$. The late phase lasts from the end of the portal venous phase until there is unequivocal clearance of microbubbles from the circulation at about 4-6 minutes $[2,19]$.

\section{Definition of Washout}

Washout is defined by a visually assessed temporal reduction in enhancement in whole or in part relative to the composite liver tissue from an earlier to a later phase, resulting in hypoenhancement at any time, including the arterial phase, portal venous phase, and late phase [19]. The peak arterial phase enhancement before washout may be either in excess of (hyperenhancement) or equal to (isoenhancement) the enhancement of the adjacent parenchyma.

\section{Significance of Washout in Differentiating Focal Liver Lesions}

Evidence has shown that washout in the portal venous phase or late phase is the most important feature for distinguishing malignant lesions from benign lesions $[4,20]$. Therefore, it has been proposed to begin the algorithmic approach for diagnosing focal liver lesions on CEUS by evaluating the presence or absence of washout $[4,21]$. In a CEUS examination using a pure blood pool contrast agent, almost all malignant nodules, including ICC and other fibrotic tumors, show washout, reflecting the lower blood volume of malignant lesions relative to the liver. It should be noted that for ICC and other fibrotic tumors, there may be discordance in the presence of late-phase washout between CEUS and CT or MRI because the contrast materials used in CT and MRI can extravasate into the interstitium and accumulate progressively in the centrally located fibrous stroma, manifesting as late-phase hyperenhancement (Fig. 1) [22-24]. Understanding of this discordance is critical to reach the imaging diagnosis of ICC if present.

Infrequent exceptions to this algorithm have been reported for both benign and malignant masses on CEUS; in particular, some well-differentiated HCCs do not show washout [8], likely due to the similar blood volume of the lesion relative to the liver. Some benign liver masses, including hepatic adenomas, focal nodular hyperplasias (FNHs), and inflammatory pseudotumors may show washout $[3,25,26]$. It should also be noted that in patients with advanced cirrhosis, the presence and degree of washout of a focal liver lesion may be affected by poor enhancement of the background parenchyma due to decreased portal venous perfusion [27] and decreased vascular volume in the cirrhotic liver. In some cases of HCC, mild or no washout during the late phase can be partly attributed to the poorly enhancing hepatic parenchyma in the background. However, this may not be related to early washout in nonhepatocellular malignancies. 


\section{Characterizing Washout by Its Onset and Degree}

In the 2017 version of CEUS LI-RADS, washout is categorized by its onset and degree (Table 1). Early washout is defined as washout that is unequivocally detectable earlier than 60 seconds after contrast injection [19]. Late washout refers to washout that is unequivocally detectable at 60 seconds or later [19]. Washout is considered mild when a nodule is hypoenhancing relative to the liver, but still shows substantial enhancement within 2 minutes after contrast injection [19]. Washout may appear marked at a later time (after 2 minutes), but if it becomes marked after 2 minutes, it is still characterized as mild. When washout occurs later than 2 minutes after contrast injection, the degree of washout is always mild. In contrast, marked washout occurs when a nodule appears almost black with minimal internal enhancement or is seen as a punched-

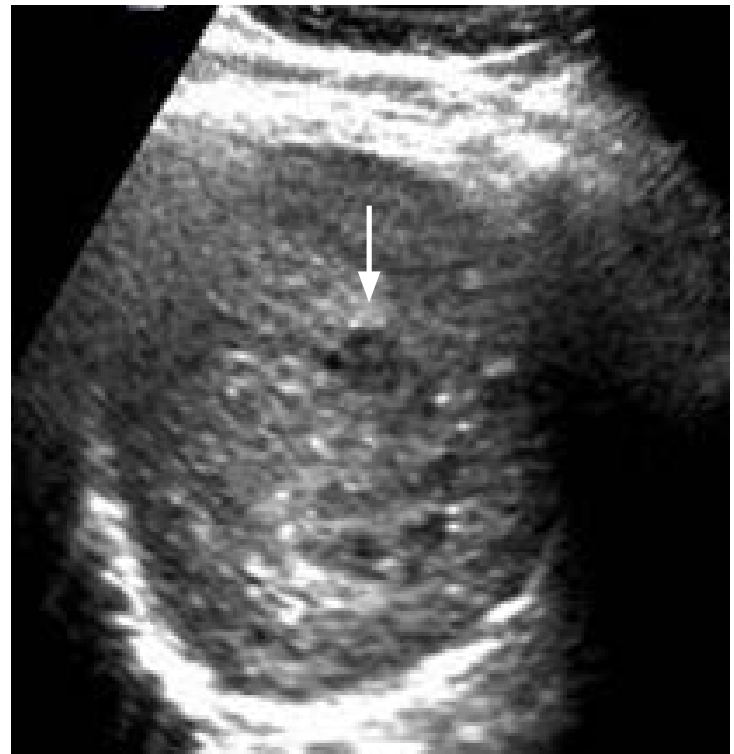

A

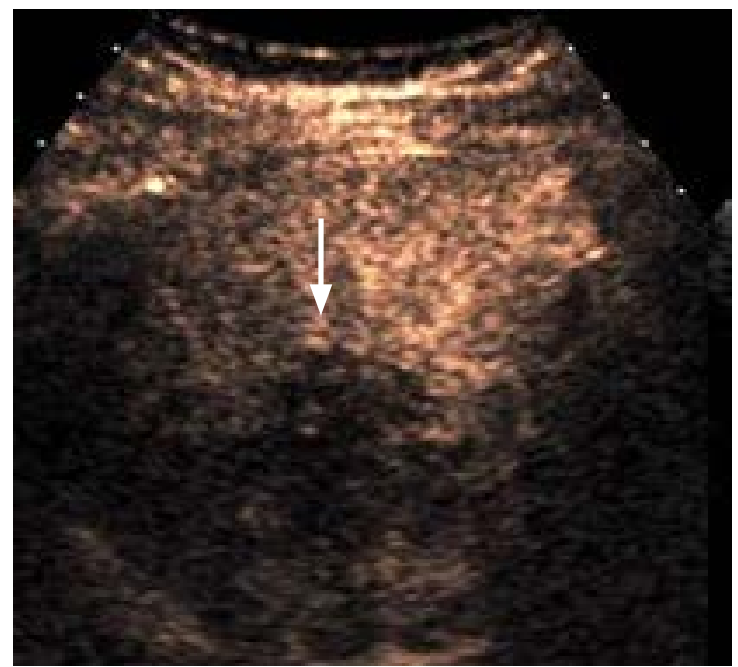

C

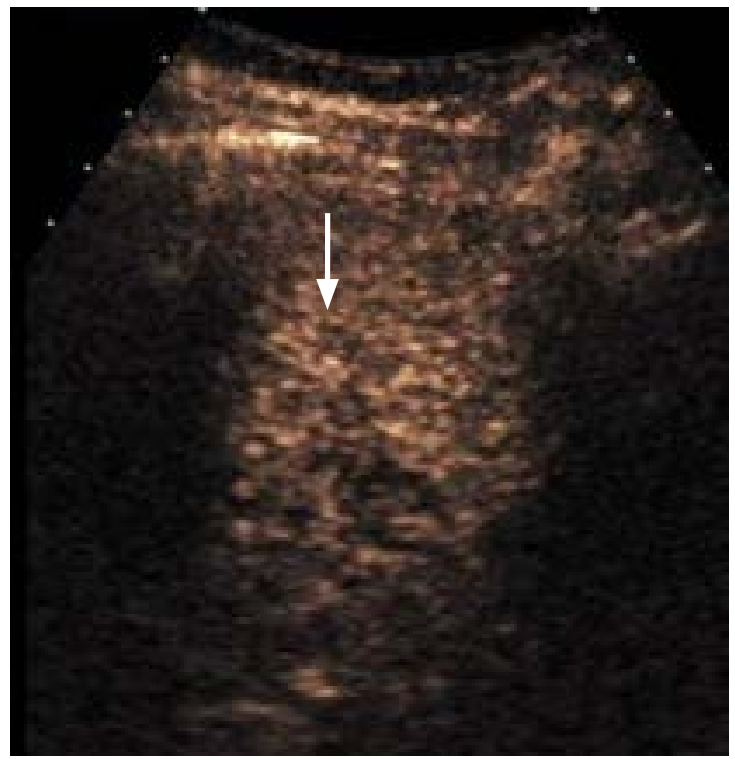

B

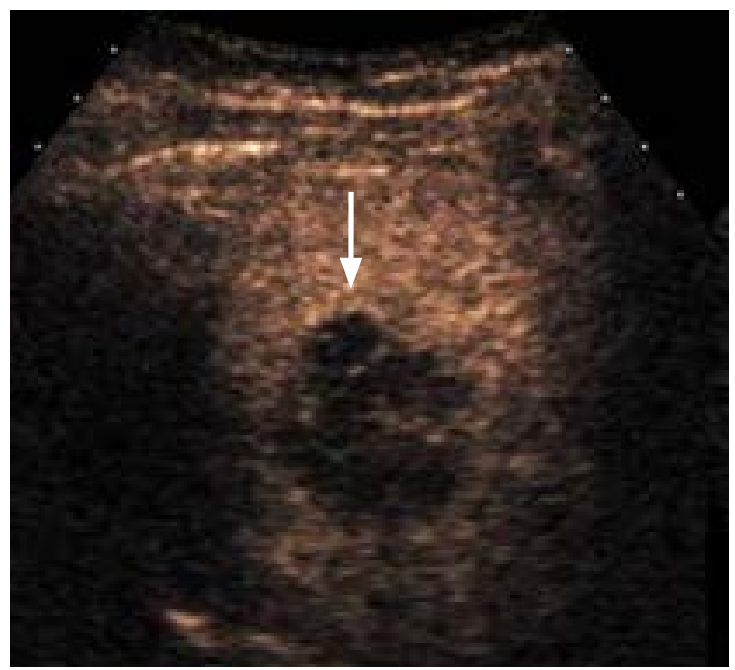

D

Fig. 1. Discordance in the presence of late-phase washout between contrast-enhanced ultrasound (CEUS) and magnetic resonance imaging (MRI) imaging of a mixed hepatocellular-cholangiocarcinoma in a 70-year-old man with nonalcoholic steatohepatitis.

Serum a-fetoprotein was elevated to 3,188.0 $\mathrm{\mu g} / \mathrm{L}$. A. A heterogeneous hypoechoic mass (arrow) is seen in the liver on a gray-scale ultrasonography. B-D. The nodule (arrow) shows hyperenhancement at 20 seconds in the arterial phase of CEUS (B) and washout at 70 seconds in the portal venous phase (C) and at 155 seconds in the late phase (D). 


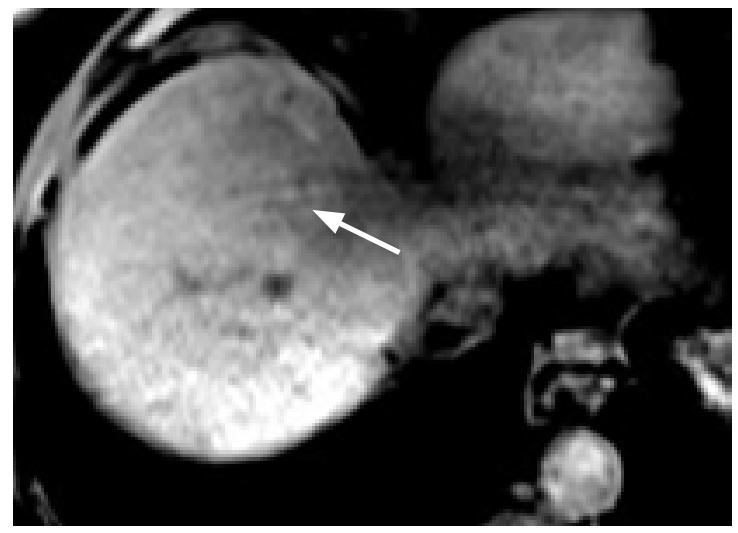

$\mathrm{E}$

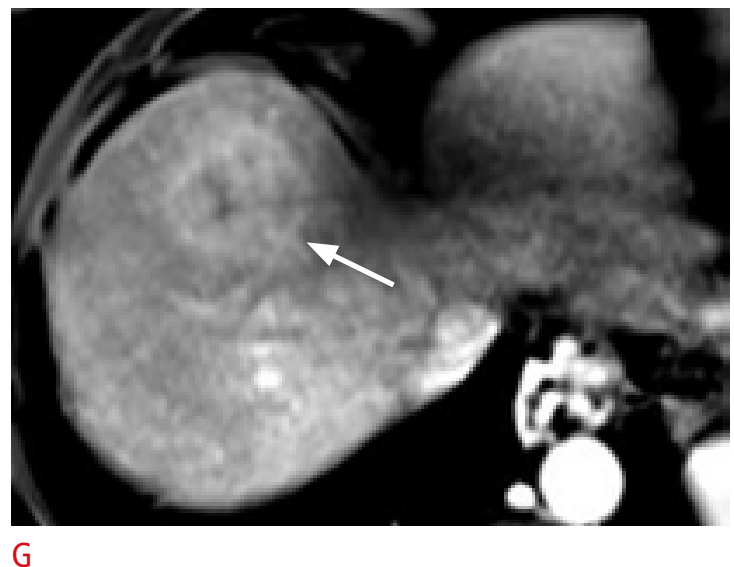

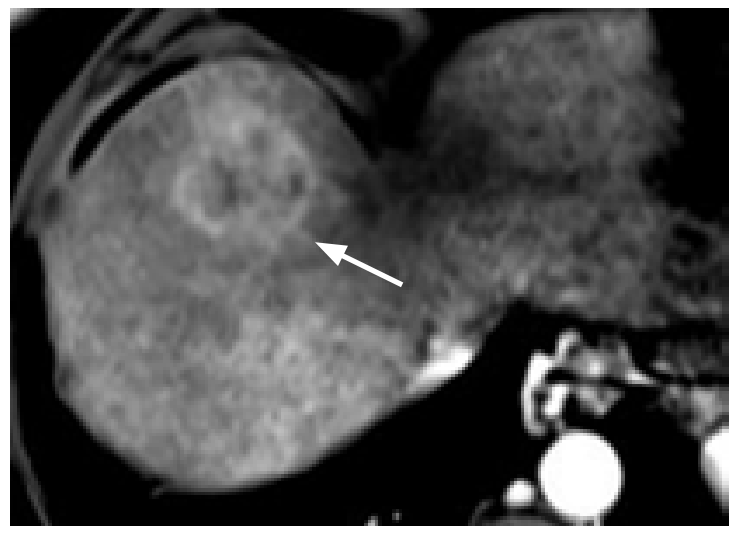

$\mathrm{F}$

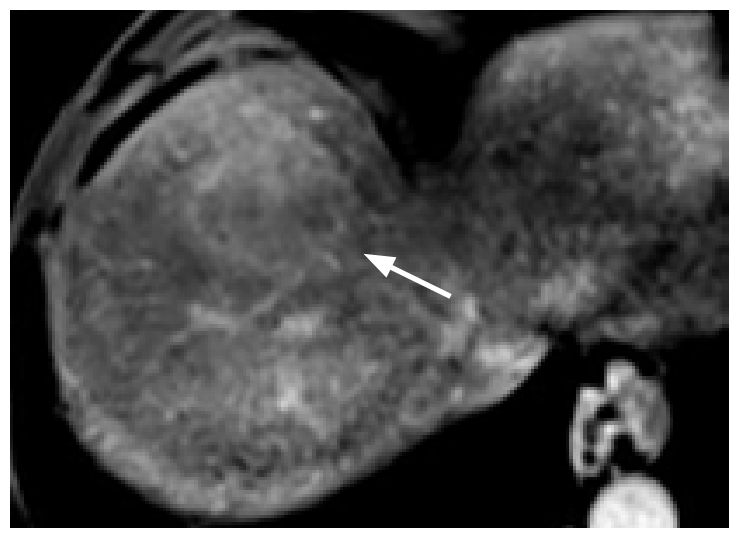

$\mathrm{H}$

Fig. 1. E. Unenhanced T1-weighted transverse MRI shows a subtle hypointense mass (arrow) in the liver. F. The mass (arrow) demonstrates heterogeneous hyperenhancement in the arterial phase. $G, H$. Hyperenhancement (arrow) persists in the portal venous phase $(G)$ and 5-minute delayed phase $(H)$.

Table 1. Characterization of washout by onset and degree

\begin{tabular}{|c|c|c|}
\hline \multirow{2}{*}{ Washout degree } & \multicolumn{2}{|c|}{ Washout onset } \\
\hline & Early (<60 sec) & Late ( $\geq 60 \mathrm{sec}$ ) \\
\hline Marked & $\begin{array}{l}\text { Typical of ICC and } \\
\text { metastases }\end{array}$ & $\begin{array}{l}\text { Suggests malignancy in } \\
\text { general, not specific for } \\
\text { any particular type }\end{array}$ \\
\hline Mild & $\begin{array}{l}\text { Suggests malignancy in } \\
\text { general, not specific for } \\
\text { any particular type }\end{array}$ & $\begin{array}{l}\text { Typical of HCC and HCC } \\
\text { precursor nodules }\end{array}$ \\
\hline
\end{tabular}

Adapted from CEUS LI-RADS v2017 CORE. Reston, VA: American College of Radiology, 2017. Available from: https://www.acr.org/-/media/ACR/Files/RADS/ LI-RADS/CEUS-LI-RADS-2017-Core.pdf?la=en, with permission of The American College of Radiology [19].

ICC, intrahepatic cholangiocarcinoma; HCC, hepatocellular carcinoma.

out lesion within 2 minutes after contrast injection [19].

ICCS are occasionally found during HCC surveillance, although the incidence of ICC is much lower than that of HCC $[28,29]$ and there are considerable differences between HCC and ICC in the treatment strategy and prognosis. Distinguishing between early and late washout and mild and marked washout is imperative for preventing misdiagnosis of ICC as HCC. The standard diagnostic hallmark of $\mathrm{HCC}$ on contrast imaging, consisting of arterial phase hyperenhancement (APHE) followed by the appearance of washout [30-34], is frequently seen on CEUS in cases of ICC in cirrhotic livers. However, subsequent studies have shown that the onset of washout occurs earlier in ICC than in HCC, mostly before 1 minute after contrast injection in ICC, and that the degree of washout is more marked in ICC than in HCC [35-39].

This information was reflected in the LR- 5 and LR-M categories of the 2017 version of CEUS LI-RADS (Table 1). CEUS LI-RADS provides a diagnostic algorithm that categorizes observations in the liver from LR-1 (definitely benign) through LR-5 (definitely HCC) according to the observed size and enhancement pattern. The criteria for LR-5 are all of the following: APHE, a nodule size of $\geq 10 \mathrm{~mm}$, and late and mild washout (Fig. 2). The APHE should show neither a rim nor a peripheral discontinuous globular pattern. The APHE is generally 
diffuse, although it may be partial. LR-M is assigned for lesions with imaging features that are probably or definitely malignant, but not HCC-specific. LR-M imaging features include rim APHE, early ( $<60$ seconds) washout, or marked washout. If any one of those features exists in a lesion, LR-M is assigned. The differential diagnoses of LR-M observations include atypical HCCS and nonhepatocellular malignancies such as ICC (Fig. 3) and metastases (Fig. 4). With this updated scheme, in a recent retrospective study of 1,006 nodules from patients with chronic liver disease at risk of HCC, the LR-5 category was $98.5 \%$ (512 of 519 ) predictive of HCC, with no misdiagnosis of pure ICC as HCC [40]. If the 2005 American Association for the Study of Liver Diseases guidelines for CEUS (i.e., hyperenhancement in the arterial phase followed by washout in the portal venous phases regardless of its time of onset or intensity) [32] had been applied, the positive predictive value for HCC would have been $94 \%$ (512 of 580) [40], markedly lower than the current data of $98.5 \%$.

However, it should also be noted that a significant proportion of
LR-M lesions on CEUS are HCCS, rather than non-hepatocellular malignancies. LR-M lesions usually require biopsy for diagnosis, in contrast to LR-5 lesions, which can be treated as HCC without further confirmation. A recent study demonstrated that 48\% (39 of 82) of LR-M nodules on CEUS were HCCS, and the remainders were non-hepatocellular malignancies [40], in concordance with previous evidence revealing that a subset of HCCs showed early washout (Fig. 5) [41].

\section{Potential Mechanisms of Rapid Washout in Non-hepatocellular Malignancies}

Prior publications have shown that the tumor differentiation of HCC is related to the onset of washout, as more poorly differentiated HCC tends to show earlier washout $[8,41,42]$. Okamoto et al. [43] suggested that earlier washout in poorly differentiated trabeculartype HCC can be explained by the presence of fewer wide tumor sinusoids that allow faster blood flow, compared to HCCs of lower

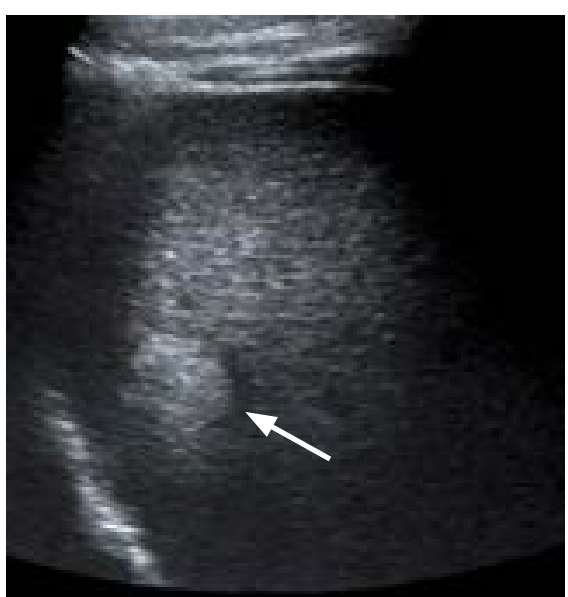

A

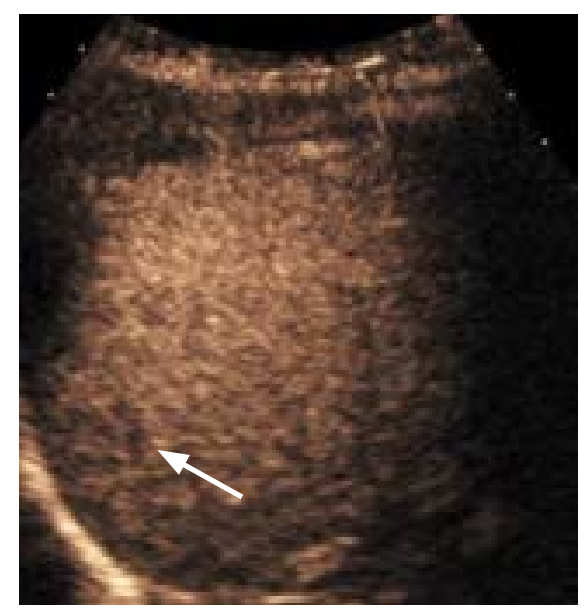

D

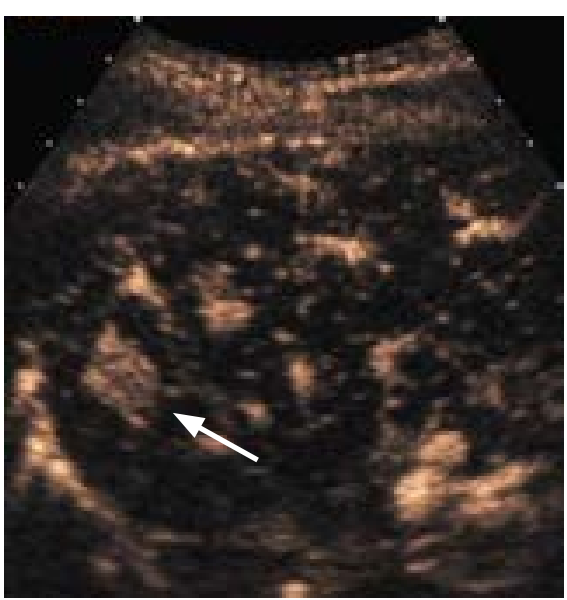

B

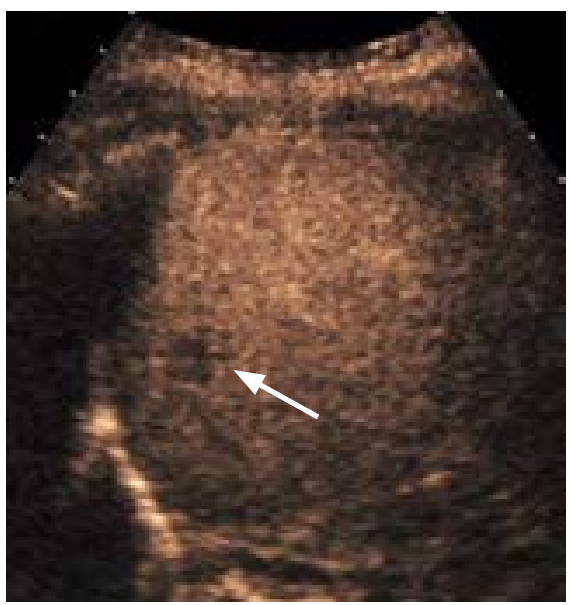

$\mathrm{E}$

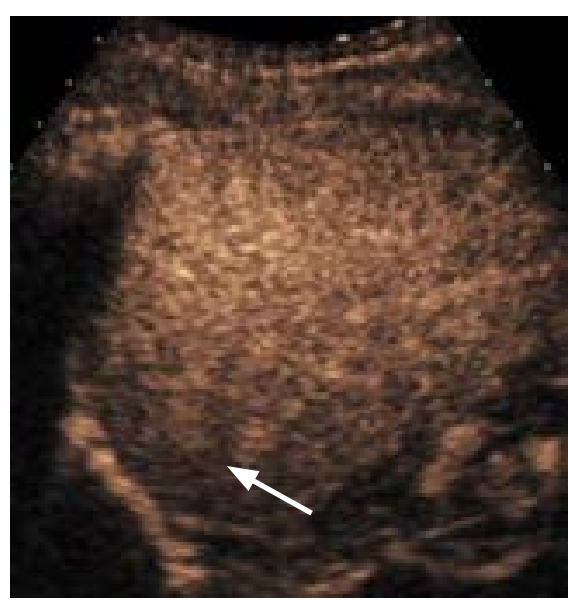

C

Fig. 2. Hepatocellular carcinoma in a 76-year-old man with chronic hepatitis B showing arterial hyperenhancement and mild and late washout on contrastenhanced ultrasonography (CEUS).

A. Gray-scale ultrasonography shows a hyperechoic nodule (arrow) in the liver. B. The nodule (arrow) shows hyperenhancement at 24 seconds in the arterial phase of CEUS. C. Washout is not apparent (arrow) at 79 seconds in the portal venous phase. D, E. The nodule (arrow) shows mild and late washout at 126 seconds (D) and at 204 seconds (E) in the late phase. 


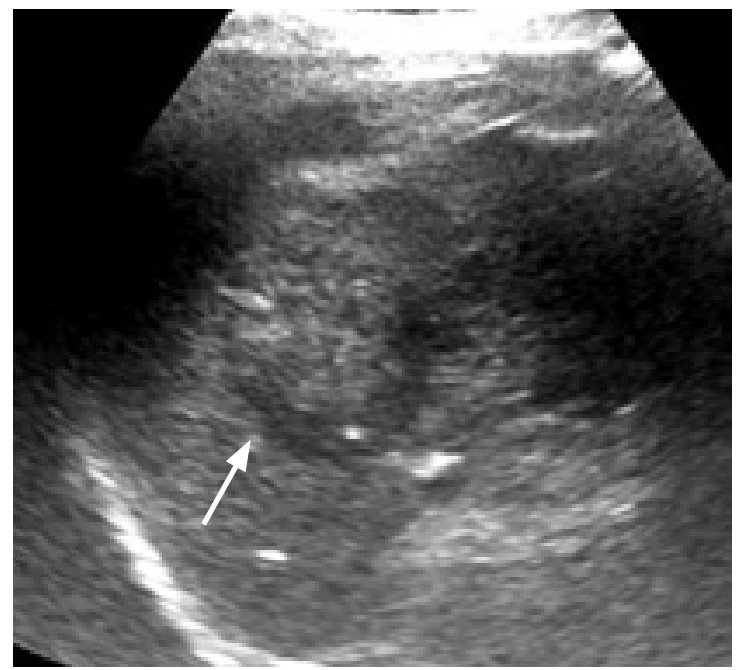

A

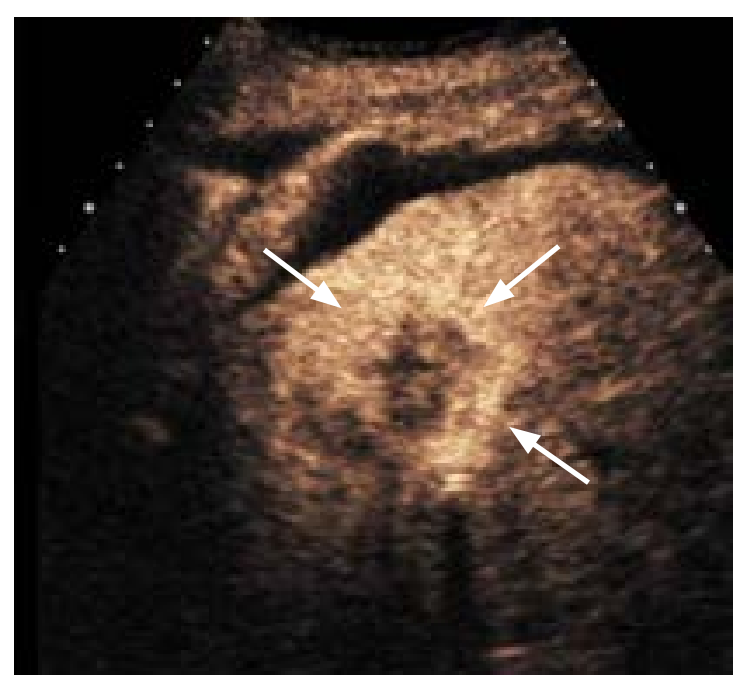

C

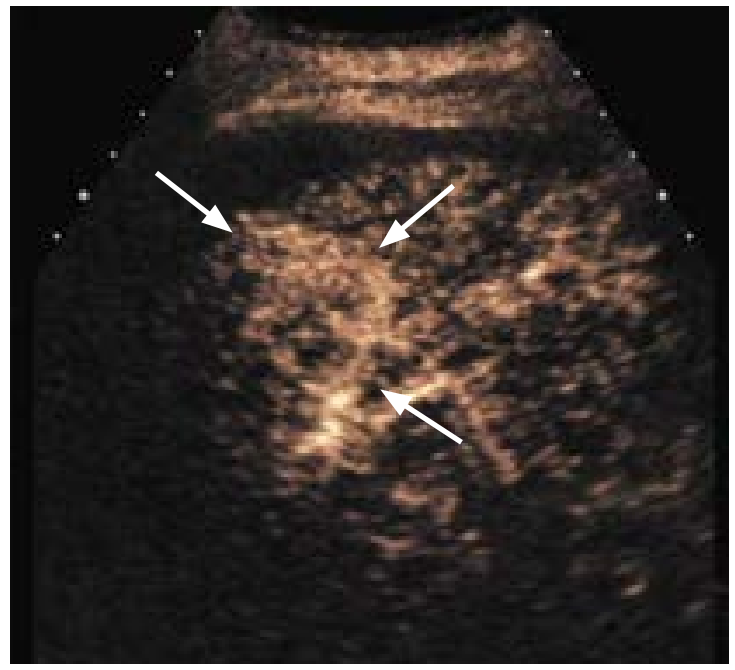

B

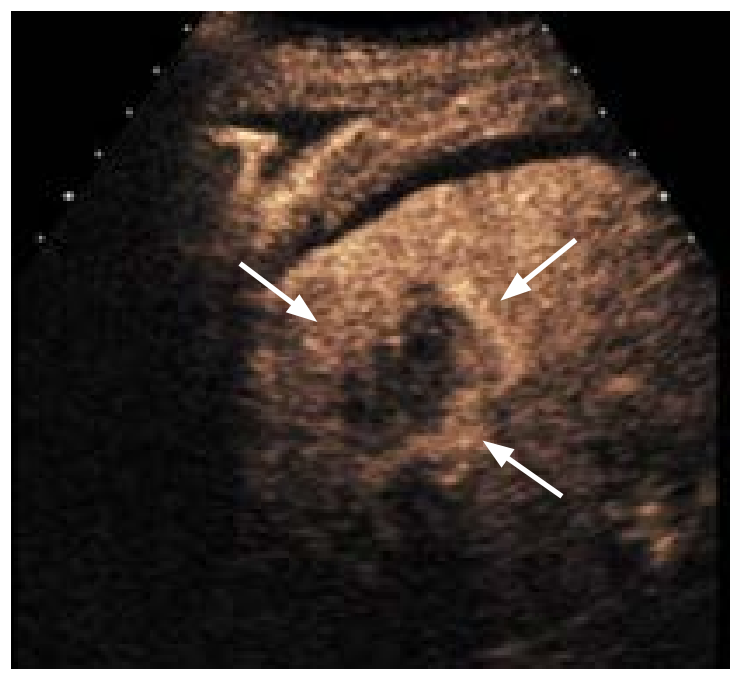

D

Fig. 3. Intrahepatic cholangiocarcinoma showing rim arterial-phase hyperenhancement and early and marked washout in a 69-year-old man.

A. Gray-scale ultrasonography shows a heterogeneously hypoechoic mass (arrow) in the liver. B, C. At 8 seconds (B) and at 25 seconds (C) in arterial phase of contrast-enhanced ultrasonography (CEUS), rim hyperenhancement (arrows) was noted. D. At 44 seconds in the portal venous phase of CEUS, washout (arrows) was seen.

histological grades. In addition, a recent study reported that washout occurring at 10-30 seconds after injection of the contrast agent was a predictor of microvascular invasion in HCC, an expression of aggressive biological behavior [44]. Furthermore, earlier washout in non-hepatocellular malignancies (i.e., ICC or metastatic adenocarcinoma) than in HCC has been extensively reported $[38,45-47]$. Given those findings in the literature, it appears that the more distinct neoplastic cells are from normal hepatocytes in their nature, the more rapidly washout occurs.

However, the biological basis of the rapidity and degree of washout is not fully understood. Multiple contributory factors might exist, including early venous drainage from the lesion, lower vascular volume of the lesion relative to the liver, and persistent enhancement of the background liver. In patients with advanced cirrhosis, late and mild washout in HCC can also be partly explained by reduced enhancement of the cirrhotic liver parenchyma, presumably due to decreased portal venous perfusion [27] and decreased vascular volume.

Regarding the earlier and more marked washout of nonhepatocellular malignancies such as ICC or metastatic 


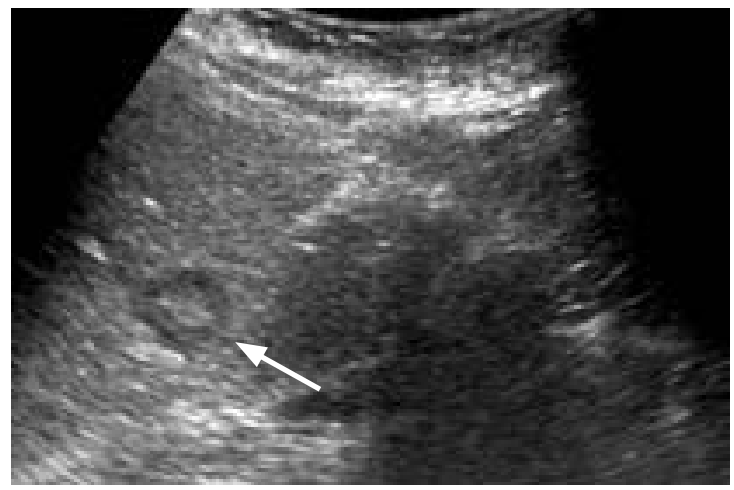

A

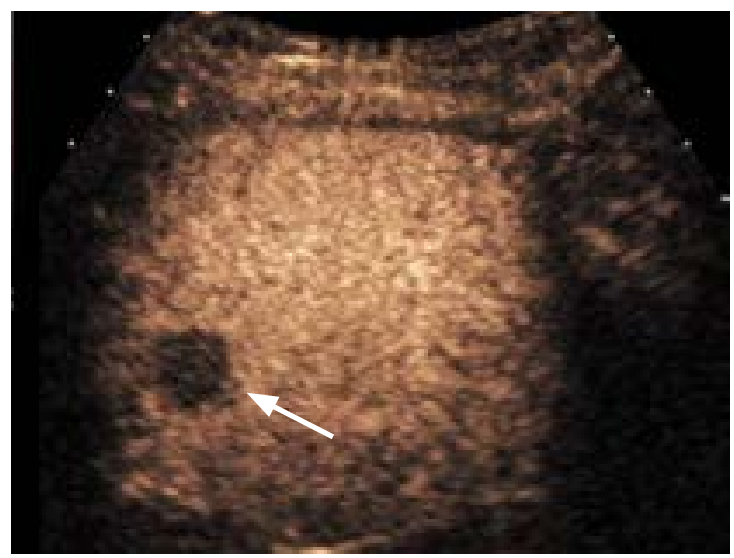

C

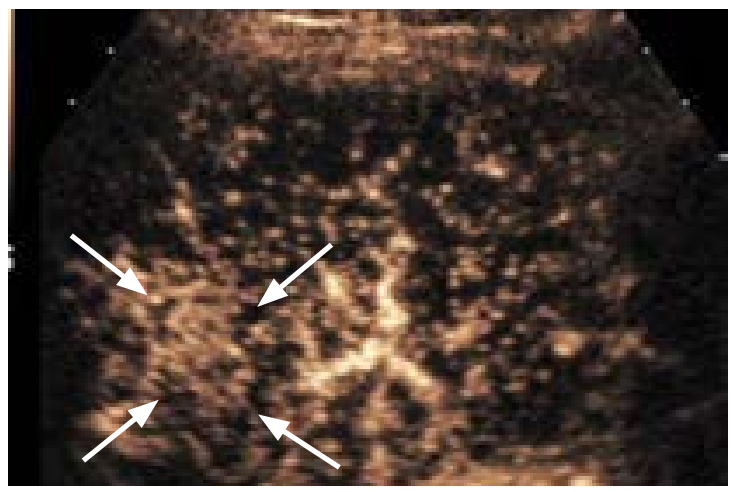

B

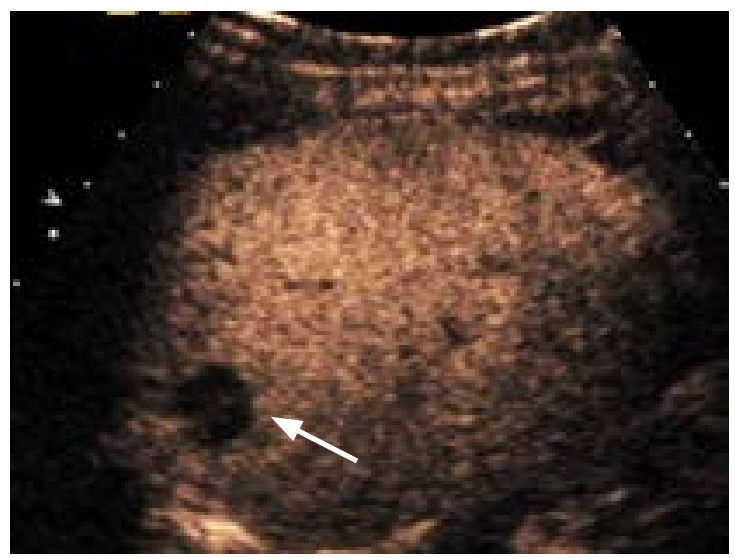

D

Fig. 4. Metastasis in a 41-year-old woman with anal cancer showing early and marked washout on contrast-enhanced ultrasonography (CEUS).

A. Gray-scale ultrasonography shows an isoechoic liver nodule with a hypoechoic halo (arrow). B. CEUS in the arterial phase shows diffuse hyperenhancement of the lesion (arrows) at 11 seconds. C, D. Marked washout (arrow) is seen at 53 seconds in the portal venous phase (C) and at 307 seconds in the late phase (D).

adenocarcinoma compared to HCC, we postulate that washout in the late phase mainly reflects the lower vascular volume of the liver lesion relative to the liver parenchyma. As the concentration of the microbubbles is uniformly distributed in the blood pool in the late phase, the degree of enhancement might depend mostly on the volume of the blood pool because the microbubble contrast agent for ultrasound is purely intravascular; thus, it is expected to be evenly distributed in the blood vessels. In a recent pilot study [48] that quantified the perfusion of hepatic lesions on CEUS, malignant lesions (HCC, ICC, metastases, and liposarcoma) showed significantly lower regional blood volume than benign lesions (FNH, adenoma, and hemangioma). In ICC and metastatic adenocarcinoma with desmoplastic reactions, fibrosis, and the absence of sinusoid-like structures, the vascular volume is particularly low.

Second, a previous study has proposed altered hemodynamics in hepatic metastases favoring early hepatic venous drainage, which may contribute to the rapid washout phenomenon. In patients with hepatic metastases, shorter arrival times and shorter times to peak in both the hepatic artery and hepatic vein, as well as a shorter hepatic artery to hepatic vein transit time, were noted on CEUS in comparison with normal volunteers [49]. These findings imply the presence of arterio-hepatic venous shunts in hepatic metastases, allowing the microbubbles to bypass the hepatic sinusoids. In contrast, Kitao et al. [50] reported that during multistep hepatocarcinogenesis, the drainage vessels of HCC changed from hepatic veins to hepatic sinusoids, and then to portal veins in the course of dedifferentiation. We suggest that these changes in the drainage vessels of HCC may be correlated to the changes in the washout onset of the nodules on CEUS. According to this proposal, when the drainage flows mainly into hepatic sinusoids and partially into the portal veins, late washout occurs. In the more advanced stage, when the portal veins become the main drainage vessels, 


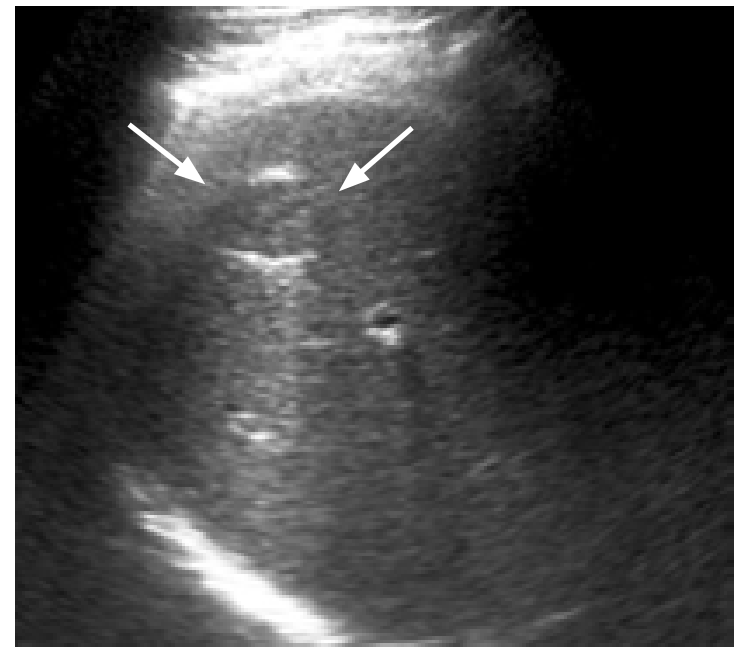

A

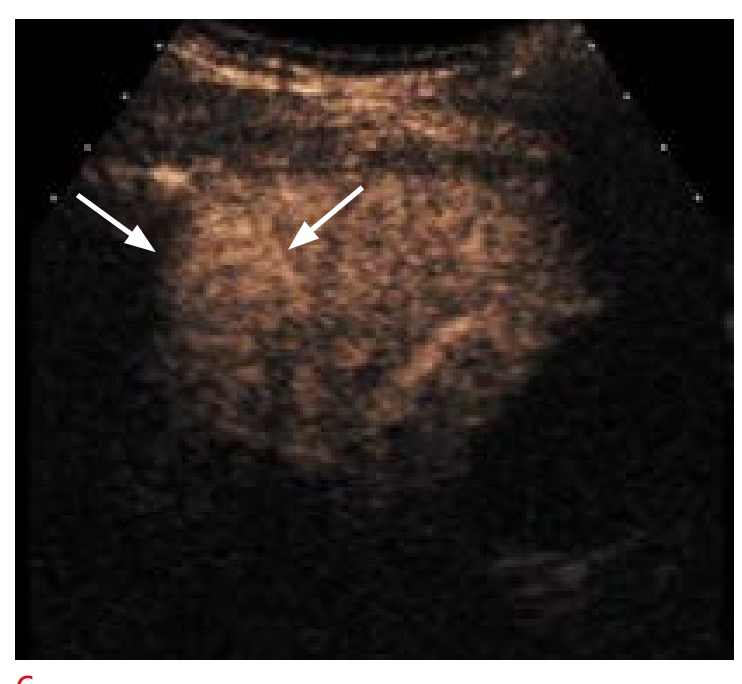

C

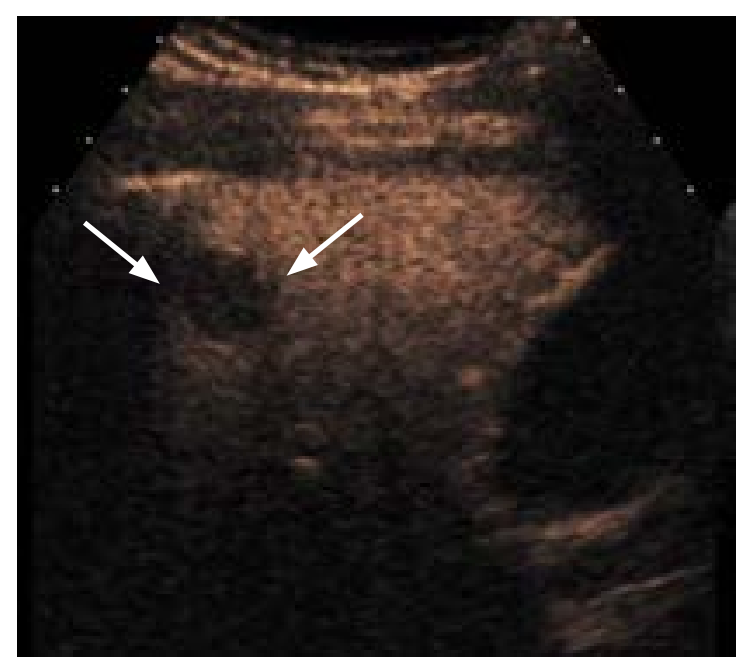

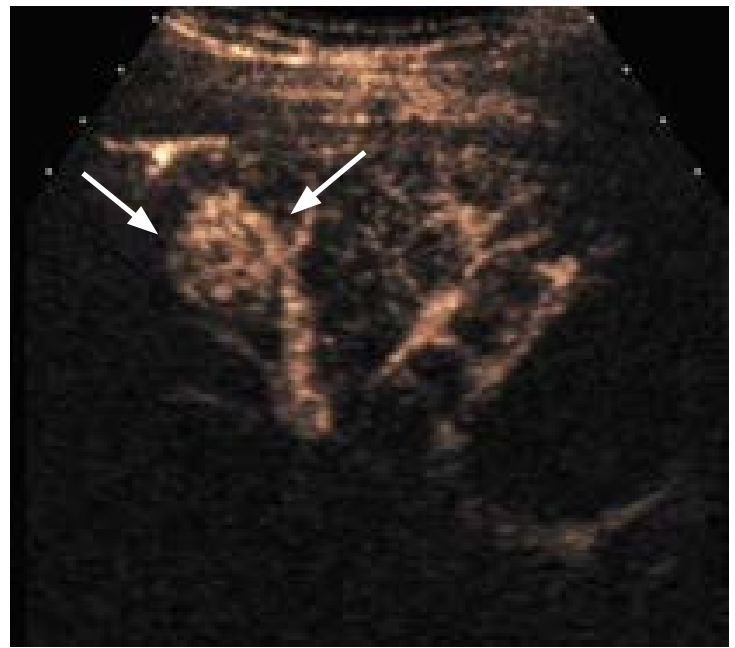

B

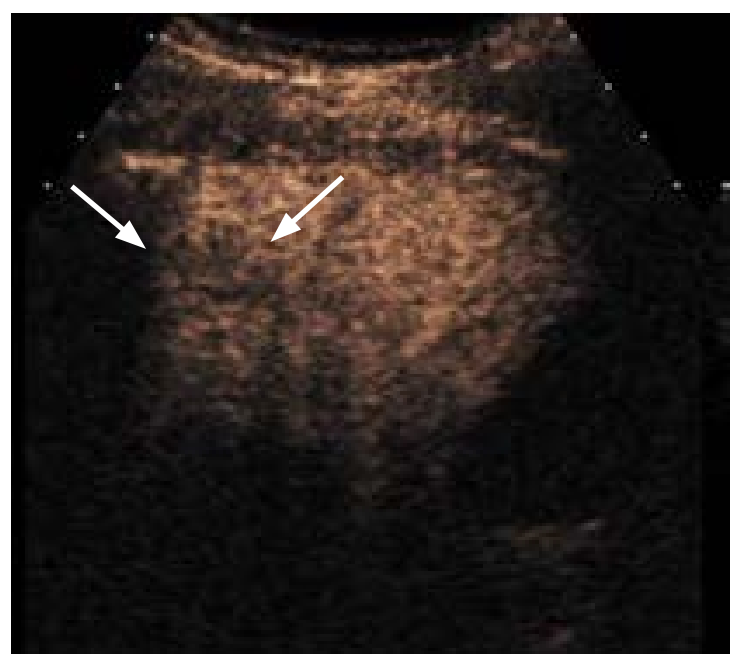

D

Fig. 5. Hepatocellular carcinoma showing early washout in a 65-year-old man with chronic hepatitis B.

Biopsy revealed moderately differentiated hepatocellular carcinoma. A. Gray-scale ultrasonography shows a 2-cm slightly hypoechoic nodule (arrows) in the liver. B, C. The nodule shows hyperenhancement (arrows) at 21 seconds (B) and 34 seconds (C) in the arterial phase scans of contrast-enhanced ultrasonography. D. At 46 seconds in the portal venous phase, early washout (arrows) is noted. E. Washout (arrows) is more prominent at 128 seconds in the late phase. 


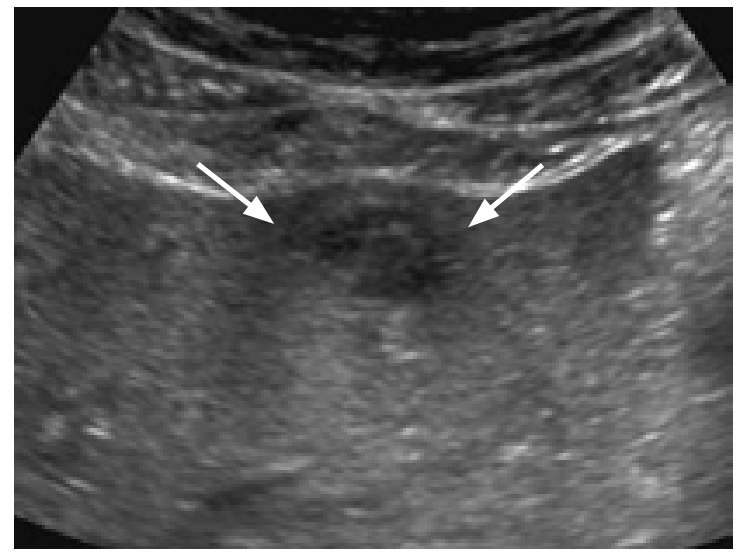

A
Fig. 6. Hepatic abscess showing early washout on contrastenhanced ultrasonography (CEUS) in a 78-year-old man with pancreatic adenocarcinoma.

A. Gray-scale ultrasonography shows a 2.0-cm hypoechoic nodule (arrows) in the liver. B. CEUS at 21 seconds in the arterial phase with the dual-imaging mode (contrast-mode on the left and grayscalemode on the right) shows isoenhancement relative to the liver (arrows). C. A CEUS scan at 56 seconds in the portal venous phase with dual-imaging mode (contrast-mode on the left and grayscalemode on the right) shows early washout (arrows), raising a suspicion for metastasis. However, intraoperational wedge biopsy of the lesion confirmed a diagnosis of abscess.

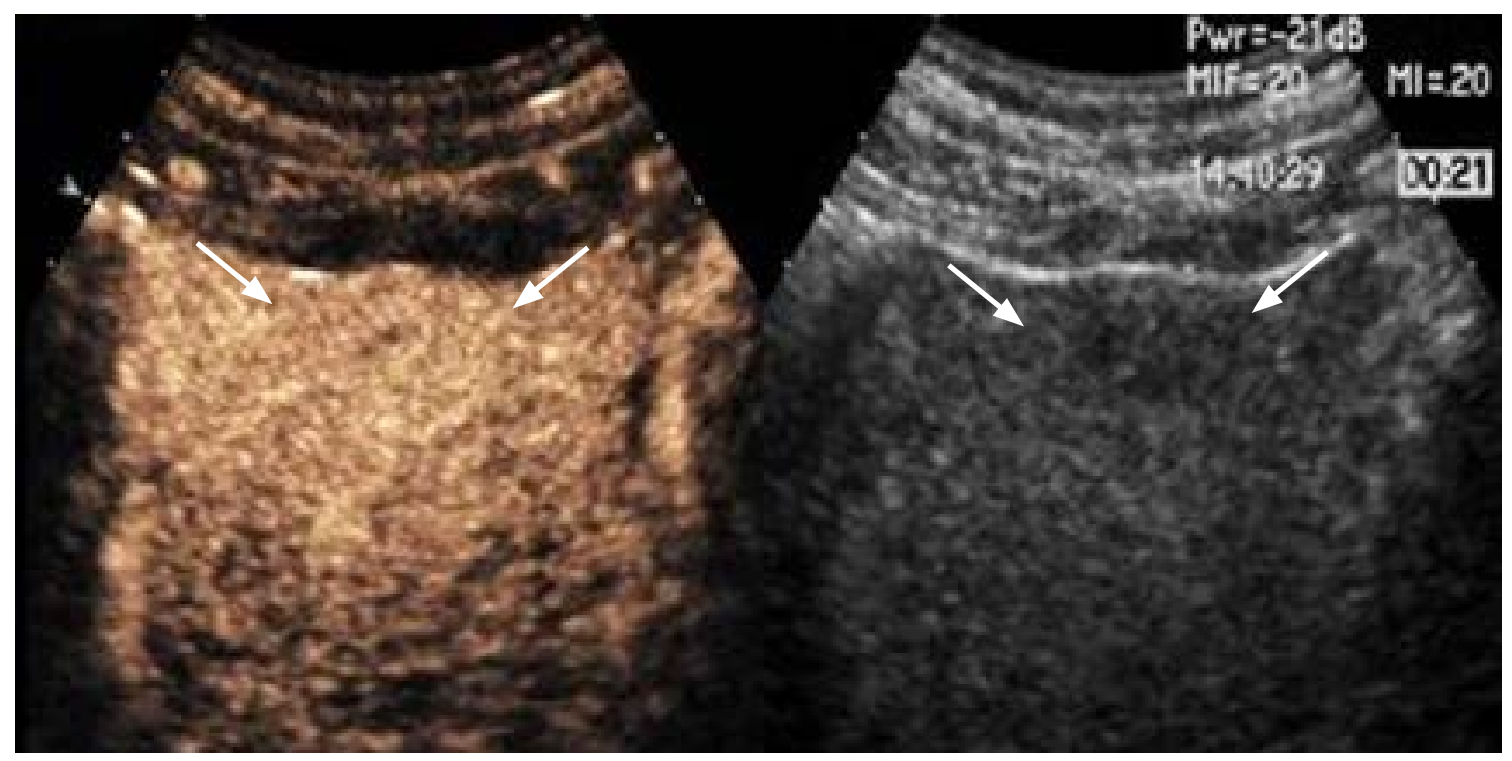

B

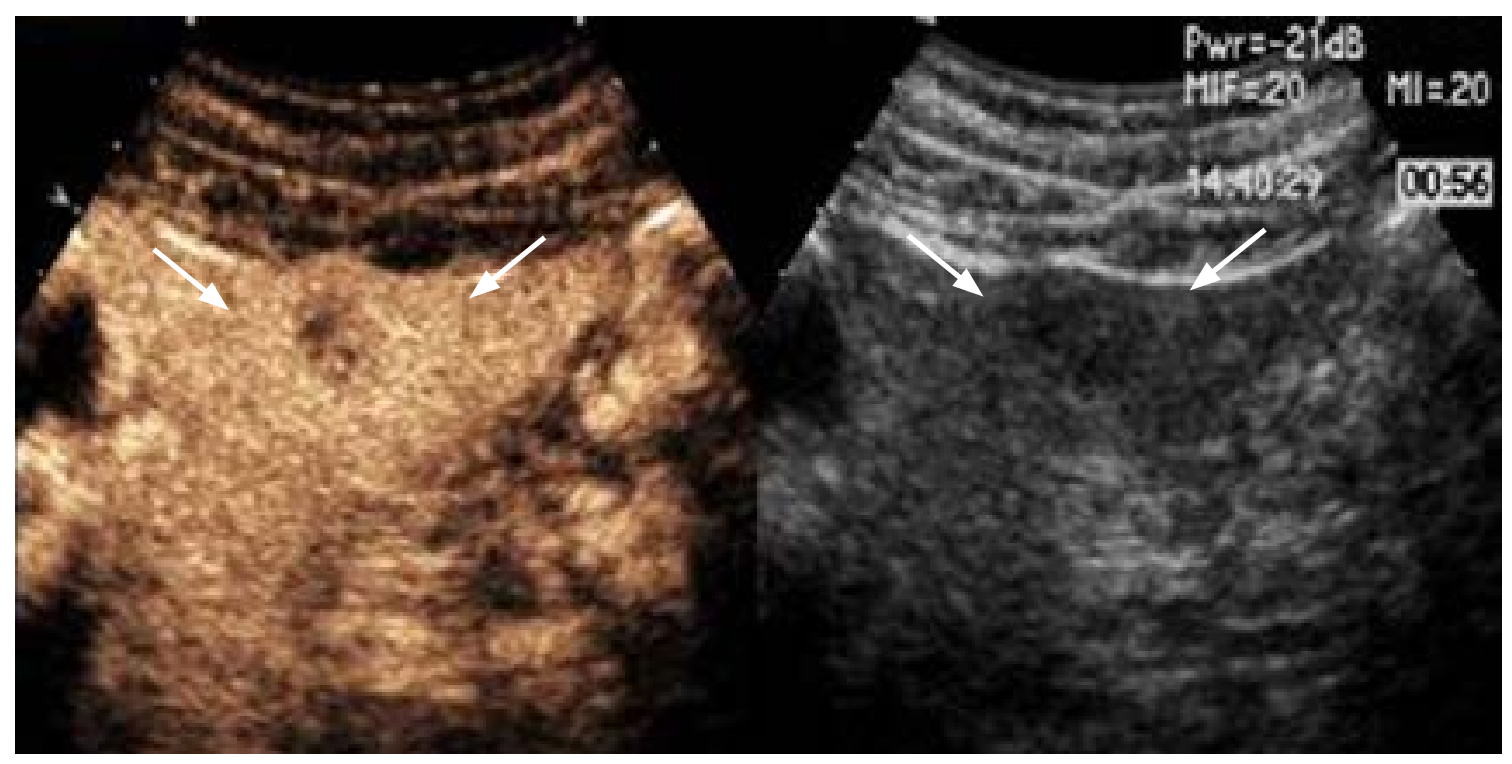

C 


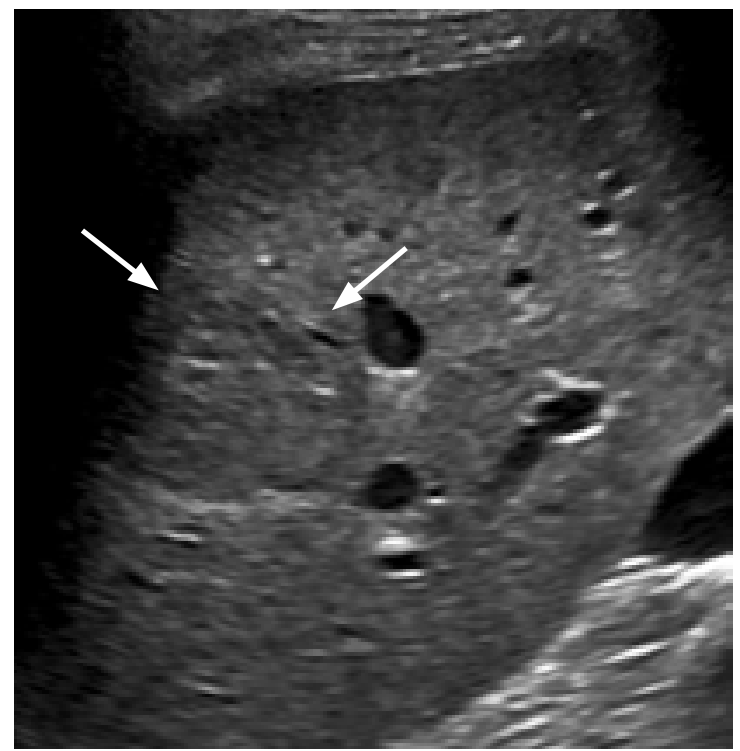

A

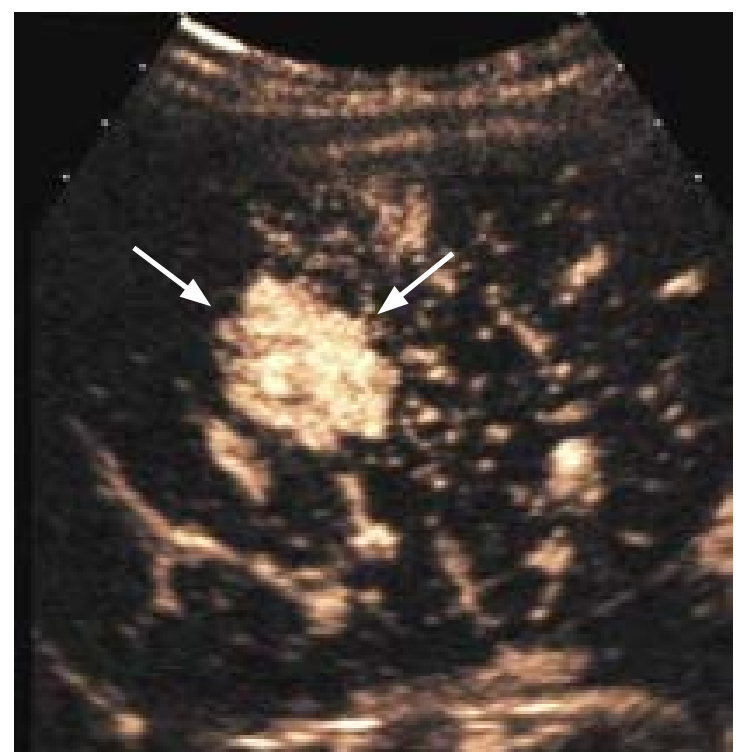

C

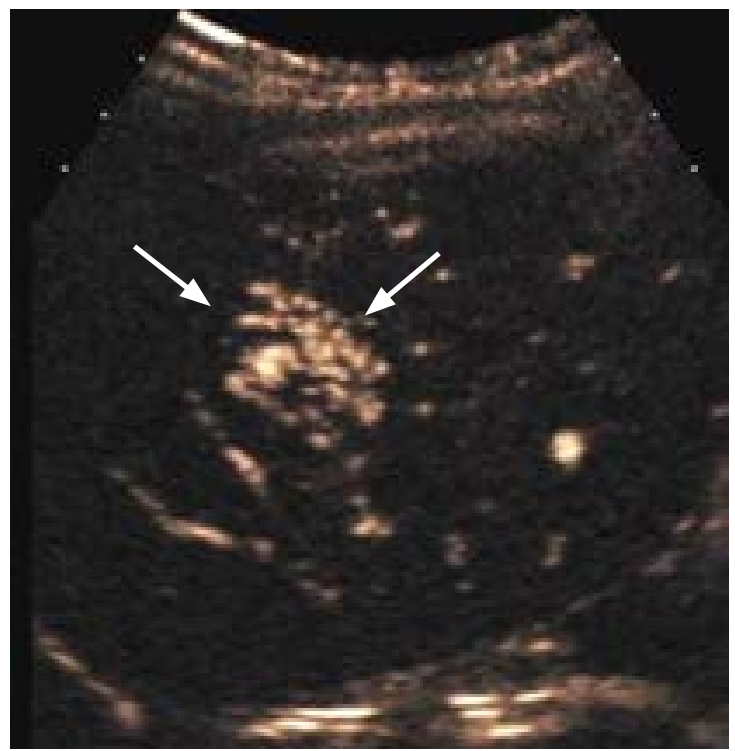

B

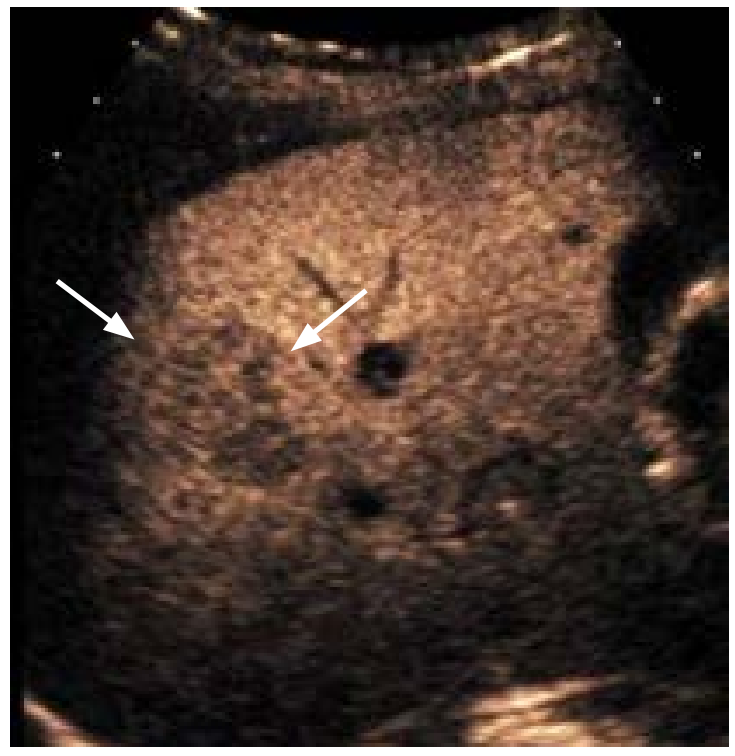

D

Fig. 7. Focal nodular hyperplasia in a 26-year-old woman showing mild washout.

A. Gray-scale sonography shows a 3.3-cm slightly hypoechoic mass (arrows) in the liver. B, C. The mass (arrows) shows hyperenhancement at 11 seconds (B) and at 13 seconds (C) in the arterial phase of contrast-enhanced ultrasonography. D. At 261 seconds in the late phase, mild washout (arrows) is noted. Biopsy revealed a focal nodular hyperplasia.

washout occurs earlier.

\section{Benign Entities Showing Washout: Potential Pitfalls}

Although the washout phenomenon of malignant tumors in general is useful to differentiate them from benign lesions, some benign entities also infrequently show washout (Fig. 6) [3,25]. Washout has been reported in $0 \%$ to $14 \%$ of FNHs on CEUS depending on the study (Fig. 7) $[25,51,52]$. In the arterial phase, real-time assessment may demonstrate the characteristic spoke-wheel pattern of APHE with an inside-to-outside, or centrifugal, filling pattern [4] in typical cases of FNH. Studies have shown that some hepatocellular adenomas [25] and inflammatory pseudotumors $[3,26]$ demonstrate washout. Adenomas often show APHE and demonstrate either sustained enhancement or mild washout in the late phase $[25,53]$. 
As approximately $30 \%$ of adenomas show mild washout in the late phase of CEUS [54,55], it may be difficult to differentiate adenoma from HCC. In such causes, the individual patient's history of risk factors for HCC and demographics are important for differentiation, and a biopsy may be required in indeterminate cases. Insufficient data exist as to whether the presence and rapidity of washout on CEUS are related to the subtypes of hepatocellular adenomas. One study reported that two of six inflammatory adenomas and one of three HNF1a-inactivated adenomas showed late washout, while one of six inflammatory adenomas and one of three HNF1a-inactive adenomas showed washout beginning from the portal venous phase [54]. Inflammatory lesions such as immature abscesses may show early and marked washout, mimicking the enhancement pattern of non-hepatocellular malignant tumors $[56,57]$. They show APHE in both the center and the periphery of the nodule more frequently than rim APHE [57].

\section{Conclusion}

CEUS is a valuable and powerful tool for the evaluation of focal liver lesions. In the CEUS approach to the diagnosis of focal liver lesions, the presence or absence of washout is important for differentiating between malignant and benign lesions. The onset and degree of washout are useful for differentiating hepatocellular and nonhepatocellular malignancies. It is also important to recognize that benign liver lesions may infrequently show washout. Radiologists should be familiar with the definition and subtypes of washout and its potential pitfalls, as well as the concept that microbubbles are purely intravascular agents.

ORCID: Hyun Kyung Yang: https://orcid.org/0000-0003-3576-9146; Hyun-Jung Jang: https://orcid.org/0000-0001-5565-7366; Yuko Kono: https://orcid.org/0000-00029357-4104; Korosh Khalili: https://orcid.org/0000-0002-3496-8744; Stephanie R. Wilson: https://orcid.org/0000-0001-6396-7612; Tae Kyoung Kim: https://orcid. org/0000-0001-5193-1428

\section{Author Contributions}

Conceptualization: Kim TK. Data acquisition: Yang HK, Jang HJ, Kim TK. Drafting of the manuscript: Yang HK, Kim TK. Critical revision of the manuscript: Yang HK, Burns PN, Jang HJ, Kono Y, Khalili K, Wilson SR, Kim TK. Approval of the final version of the manuscript: all authors.

\section{Conflict of Interest}

No potential conflict of interest relevant to this article was reported.

\section{References}

1. D'Onofrio M, Crosara S, De Robertis R, Canestrini S, Mucelli RP. Contrast-enhanced ultrasound of focal liver lesions. AJR Am J Roentgenol 2015;205:W56-W66.

2. Claudon M, Dietrich CF, Choi BI, Cosgrove DO, Kudo M, Nolsoe CP, et al. Guidelines and good clinical practice recommendations for contrast enhanced ultrasound (CEUS) in the liver: update 2012: a WFUMB-EFSUMB initiative in cooperation with representatives of AFSUMB, AIUM, ASUM, FLAUS and ICUS. Ultraschall Med 2013;34:11-29.

3. Bhayana D, Kim TK, Jang HJ, Burns PN, Wilson SR. Hypervascular liver masses on contrast-enhanced ultrasound: the importance of washout. AJR Am J Roentgenol 2010;194:977-983.

4. Wilson SR, Burns PN. An algorithm for the diagnosis of focal liver masses using microbubble contrast-enhanced pulse-inversion sonography. AJR Am J Roentgenol 2006;186:1401-1412.

5. Claudon M, Cosgrove D, Albrecht T, Bolondi L, Bosio M, Calliada F, et al. Guidelines and good clinical practice recommendations for contrast enhanced ultrasound (CEUS): update 2008. Ultraschal Med 2008;29:28-44.

6. von Herbay $A$, Vogt $C$, Willers $R$, Haussinger $D$. Real-time imaging with the sonographic contrast agent SonoVue: differentiation between benign and malignant hepatic lesions. J Ultrasound Med 2004;23:1557-1568.

7. Murphy-Lavallee J, Jang HJ, Kim TK, Burns PN, Wilson SR. Are metastases really hypovascular in the arterial phase? The perspective based on contrast-enhanced ultrasonography. $J$ Ultrasound Med 2007;26:1545-1556.

8. Jang HJ, Kim TK, Burns PN, Wilson SR. Enhancement patterns of hepatocellular carcinoma at contrast-enhanced US: comparison with histologic differentiation. Radiology 2007;244:898-906.

9. Jo PC, Jang HJ, Burns PN, Burak KW, Kim TK, Wilson SR. Integration of contrast-enhanced US into a multimodality approach to imaging of nodules in a cirrhotic liver: how I do it. Radiology 2017;282:317331.

10. Rimola J, Forner A, Reig M, Vilana R, de Lope CR, Ayuso C, et al. Cholangiocarcinoma in cirrhosis: absence of contrast washout in delayed phases by magnetic resonance imaging avoids misdiagnosis of hepatocellular carcinoma. Hepatology 2009:50:791-798.

11. Vilana R, Forner A, Bianchi L, Garcia-Criado A, Rimola J, de Lope $C R$, et al. Intrahepatic peripheral cholangiocarcinoma in cirrhosis patients may display a vascular pattern similar to hepatocellular carcinoma on contrast-enhanced ultrasound. Hepatology 2010;51:2020-2029.

12. Loyer EM, Chin H, DuBrow RA, David CL, Eftekhari F, Charnsangave C. Hepatocellular carcinoma and intrahepatic peripheral cholangiocarcinoma: enhancement patterns with quadruple phase 
helical CT: a comparative study. Radiology 1999;212:866-875.

13. Kim SJ, Lee JM, Han JK, Kim KH, Lee JY, Choi BI. Peripheral massforming cholangiocarcinoma in cirrhotic liver. AJR Am J Roentgenol 2007; 189:1428-1434.

14. Iavarone M, Piscaglia F, Vavassori S, Galassi M, Sangiovanni A, Venerandi L, et al. Contrast enhanced CT-scan to diagnose intrahepatic cholangiocarcinoma in patients with cirrhosis. J Hepatol 2013;58:1188-1193.

15. Gardeur D, Lautrou J, Millard JC, Berger N, Metzger J. Pharmacokinetics of contrast media: experimental results in dog and man with CT implications. J Comput Assist Tomogr 1980;4:178-185.

16. Donahue KM, Burstein D, Manning WJ, Gray ML. Studies of GdDTPA relaxivity and proton exchange rates in tissue. Magn Reson Med 1994;32:66-76.

17. Miles KA, Charnsangavej C, Lee FT, Fishman EK, Horton K, Lee TY. Application of $\mathrm{CT}$ in the investigation of angiogenesis in oncology. Acad Radiol 2000;7:840-850.

18. Jain R. Vascular and interstitial physiology of tumours: role in cancer detection and treatment. In: Bicknell $R$, Lewis CE, Ferrara N, eds. Tumour angiogenesis. Oxford: Oxford University Press, 1997;45-59.

19. CEUS LI-RADS v2017 CORE [Internet]. Reston, VA: American College of Radiology, 2017 [cited 2018 May 5]. Available from: https://www.acr.org/-/media/ACR/Files/RADS/LI-RADS/CEUS-LIRADS-2017-Core.pdf?la=en.

20. D'Onofrio M, Martone E, Faccioli N, Zamboni G, Malago R, Mucelli RP. Focal liver lesions: sinusoidal phase of CEUS. Abdom Imaging 2006;31:529-536.

21. Burrowes DP, Medellin A, Harris AC, Milot L, Wilson SR. Contrastenhanced US approach to the diagnosis of focal liver masses. Radiographics 2017;37:1388-1400.

22. Burns PN, Wilson SR. Focal liver masses: enhancement patterns on contrast-enhanced images: concordance of US scans with CT scans and MR images. Radiology 2007;242:162-174.

23. D'Onofrio M, Vecchiato F, Cantisani V, Barbi E, Passamonti M, Ricci $P$, et al. Intrahepatic peripheral cholangiocarcinoma (IPCC): comparison between perfusion ultrasound and $\mathrm{CT}$ imaging. Radiol Med 2008;113:76-86.

24. D'Onofrio M, Crosara S, De Robertis R, Canestrini S, Cantisani V, Morana $\mathrm{G}$, et al. Malignant focal liver lesions at contrast-enhanced ultrasonography and magnetic resonance with hepatospecific contrast agent. Ultrasound 2014;22:91-98.

25. Kim TK, Jang HJ, Burns PN, Murphy-Lavallee J, Wilson SR. Focal nodular hyperplasia and hepatic adenoma: differentiation with low-mechanical-index contrast-enhanced sonography. AJR Am J Roentgenol 2008;190:58-66.

26. Shang J, Wang YY, Dang Y, Zhang XJ, Song Y, Ruan LT. An inflammatory myofibroblastic tumor in the transplanted liver displaying quick wash-in and wash-out on contrast-enhanced ultrasound: a case report. Medicine (Baltimore) 2017;96:e9024.

27. Vignaux O, Legmann P, Coste J, Hoeffel C, Bonnin A. Cirrhotic liver enhancement on dual-phase helical CT: comparison with noncirrhotic livers in 146 patients. AJR Am J Roentgenol 1999;173:1193-1197.

28. El-Serag HB, Engels EA, Landgren O, Chiao E, Henderson L, Amaratunge $\mathrm{HC}$, et al. Risk of hepatobiliary and pancreatic cancers after hepatitis $C$ virus infection: a population-based study of U.S. veterans. Hepatology 2009;49:116-123.

29. Yamamoto S, Kubo S, Hai S, Uenishi T, Yamamoto T, Shuto T, et al. Hepatitis $C$ virus infection as a likely etiology of intrahepatic cholangiocarcinoma. Cancer Sci 2004;95:592-595.

30. Italian Association for the Study of the Liver (AISF); AISF Expert Panel; AISF Coordinating Committee, Bolondi L, Cillo U, Colombo M, et al. Position paper of the Italian Association for the Study of the Liver (AISF): the multidisciplinary clinical approach to hepatocellular carcinoma. Dig Liver Dis 2013;45:712-723.

31. Sherman M, Burak K, Maroun J, Metrakos P, Knox JJ, Myers RP, et al. Multidisciplinary Canadian consensus recommendations for the management and treatment of hepatocellular carcinoma. Curr Oncol 2011;18:228-240.

32. Bruix J, Sherman M; American Association for the Study of Liver Diseases. Management of hepatocellular carcinoma: an update. Hepatology 2011;53:1020-1022.

33. European Association for the Study of the Liver; European Organisation for Research and Treatment of Cancer. EASLEORTC clinical practice guidelines: management of hepatocellular carcinoma. J Hepatol 2012;56:908-943.

34. Kono Y, Lyshchik A, Cosgrove D, Dietrich CF, Jang HJ, Kim TK, et al. Contrast enhanced ultrasound (CEUS) Liver Imaging Reporting and Data System (LI-RADS(R)): the official version by the American College of Radiology (ACR). Ultraschall Med 2017;38:85-86.

35. de Sio I, Iadevaia MD, Vitale LM, Niosi M, Del Prete A, de Sio C, et al. Optimized contrast-enhanced ultrasonography for characterization of focal liver lesions in cirrhosis: a single-center retrospective study. United European Gastroenterol J 2014;2:279287.

36. Strobel D, Bernatik T, Blank W, Schuler A, Greis C, Dietrich CF, et al. Diagnostic accuracy of CEUS in the differential diagnosis of small $(\leq 20 \mathrm{~mm})$ and subcentimetric $(\leq 10 \mathrm{~mm})$ focal liver lesions in comparison with histology: results of the DEGUM multicenter trial. Ultraschall Med 2011;32:593-597.

37. Yuan $M X$, Li R, Zhang $X H$, Tang $C L$, Guo YL, Guo DY, et al. Factors affecting the enhancement patterns of intrahepatic cholangiocarcinoma (ICC) on contrast-enhanced ultrasound (CEUS) and their pathological correlations in patients with a single lesion. Ultraschall Med 2016;37:609-618.

38. Wildner D, Bernatik T, Greis C, Seitz K, Neurath MF, Strobel D. CEUS in hepatocellular carcinoma and intrahepatic cholangiocellular 
carcinoma in 320 patients: early or late washout matters: a subanalysis of the DEGUM multicenter trial. Ultraschall Med 2015;36:132-139.

39. Liu GJ, Wang W, Lu MD, Xie XY, Xu HX, Xu ZF, et al. Contrastenhanced ultrasound for the characterization of hepatocellular carcinoma and intrahepatic cholangiocarcinoma. Liver Cancer 2015;4:241-252.

40. Terzi E, lavarone M, Pompili M, Veronese L, Cabibbo G, Fraquelli M, et al. Contrast ultrasound LI-RADS LR-5 identifies hepatocellular carcinoma in cirrhosis in a multicenter restropective study of 1,006 nodules. J Hepatol 2018;68:485-492.

41. Feng Y, Qin XC, Luo Y, Li YZ, Zhou X. Efficacy of contrast-enhanced ultrasound washout rate in predicting hepatocellular carcinoma differentiation. Ultrasound Med Biol 2015;41:1553-1560.

42. Nicolau C, Catala V, Vilana R, Gilabert R, Bianchi L, Sole M, et al. Evaluation of hepatocellular carcinoma using SonoVue, a second generation ultrasound contrast agent: correlation with cellular differentiation. Eur Radiol 2004;14:1092-1099.

43. Okamoto D, Yoshimitsu K, Nishie A, Tajima T, Asayama Y, Ishigami K, et al. Enhancement pattern analysis of hypervascular hepatocellular carcinoma on dynamic MR imaging with histopathological correlation: validity of portal phase imaging for predicting tumor grade. Eur J Radiol 2012;81:1116-1121.

44. Zhu W, Qing X, Yan F, Luo Y, Li Y, Zhou X. Can the contrast-enhanced ultrasound washout rate be used to predict microvascular invasion in hepatocellular carcinoma? Ultrasound Med Biol 2017;43:15711580.

45. Chen LD, Xu HX, Xie XY, Xie XH, Xu ZF, Liu GJ, et al. Intrahepatic cholangiocarcinoma and hepatocellular carcinoma: differential diagnosis with contrast-enhanced ultrasound. Eur Radiol 2010;20:743-753.

46. Li R, Yuan MX, Ma KS, Li XW, Tang CL, Zhang XH, et al. Detailed analysis of temporal features on contrast enhanced ultrasound may help differentiate intrahepatic cholangiocarcinoma from hepatocellular carcinoma in cirrhosis. PLoS One 2014;9:e98612.

47. Dietrich CF, Cui XW, Boozari B, Hocke M, Ignee A. Contrastenhanced ultrasound (CEUS) in the diagnostic algorithm of hepatocellular and cholangiocellular carcinoma, comments on the
AASLD guidelines. Ultraschall Med 2012;33 Suppl 1:S57-S66.

48. Beyer LP, Pregler B, Wiesinger I, Stroszczynski C, Wiggermann P, Jung EM. Continuous dynamic registration of microvascularization of liver tumors with contrast-enhanced ultrasound. Radiol Res Pract 2014;2014:347416.

49. Zhou JH, Li AH, Cao LH, Jiang HH, Liu LZ, Pei XQ, et al. Haemodynamic parameters of the hepatic artery and vein can detect liver metastases: assessment using contrast-enhanced ultrasound. Br J Radiol 2008;81:113-119.

50. Kitao A, Zen Y, Matsui O, Gabata T, Nakanuma Y. Hepatocarcinogenesis: multistep changes of drainage vessels at CT during arterial portography and hepatic arteriography: radiologic-pathologic correlation. Radiology 2009;252:605-614.

51. Bartolotta TV, Taibbi A, Brancatelli G, Matranga D, Tumbarello $M$, Midiri $M$, et al. Imaging findings of hepatic focal nodular hyperplasia in men and women: are they really different? Radiol Med 2014;119:222-230.

52. Bertin C, Egels $S$, Wagner $M$, Huynh-Charlier I, Vilgrain V, Lucidarme O. Contrast-enhanced ultrasound of focal nodular hyperplasia: a matter of size. Eur Radiol 2014;24:2561-2571.

53. Trillaud H, Bruel JM, Valette PJ, Vilgrain V, Schmutz G, Oyen R, et al. Characterization of focal liver lesions with SonoVue-enhanced sonography: international multicenter-study in comparison to CT and MRI. World J Gastroenterol 2009;15:3748-3756.

54. Wang W, Liu JY, Yang Z, Wang YF, Shen SL, Yi FL, et al. Hepatocellular adenoma: comparison between real-time contrastenhanced ultrasound and dynamic computed tomography. Springerplus 2016;5:951.

55. Zhu XL, Chen P, Guo H, Zhang N, Hou WJ, Li XY, et al. Contrastenhanced ultrasound for the diagnosis of hepatic adenoma. J Int Med Res 2011;39:920-928.

56. Kong WT, Wang WP, Huang BJ, Ding H, Mao F. Value of wash-in and wash-out time in the diagnosis between hepatocellular carcinoma and other hepatic nodules with similar vascular pattern on contrastenhanced ultrasound. J Gastroenterol Hepatol 2014;29:576-580.

57. Kong WT, Wang WP, Cai H, Huang BJ, Ding H, Mao F. The analysis of enhancement pattern of hepatic inflammatory pseudotumor on contrast-enhanced ultrasound. Abdom Imaging 2014;39:168-174. 